\title{
História em Quadrinhos: uma Abordagem do Percurso a sua Inserção Oficial no Ensino
}

\author{
Comics: an Approach of the Route to its Official Insertion in Teaching
}

Lucinete Ornagui de Oliveira Nakamura ${ }^{\mathrm{a}}$; Ana Graciela Mendes Fernandes da Fonseca Voltolini*a; José Serafim Bertoloto ${ }^{\text {ab }}$

anniversidade de Cuiabá, Programa de Pós-Graduação Stricto Sensu em Ensino. MT, Brasil.

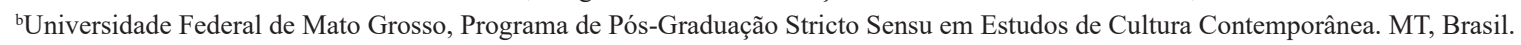

*E-mail: fonsecaanagraciela@gmail.com

\begin{abstract}
Resumo
O uso da História em Quadrinhos, no contexto escolar, ganha espaço pela popularidade, enquanto meio de comunicação de massa, pela ludicidade e apelo visual. Dessa forma, pode representar a possibilidade de fortalecer o ensino e a prática da leitura, contribuindo também para a produção textual, bem como para a compreensão de diferentes conteúdos sistematizados. Entretanto, nem sempre foi assim, houve uma época em que a História em Quadrinhos era vista por pais, educadores e demais membros da sociedade como um meio para alienação dos leitores. Nesse contexto, o objetivo deste artigo é apresentar o percurso da História em Quadrinhos até seu ingresso oficial no ensino, destacando a trajetória, a resistência e a aceitabilidade por parte dos educadores. Para isso, o artigo recorre a documentos oficiais como os Parâmetros Curriculares Nacionais e a Base Nacional Comum Curricular. Autores como Iannone e Iannone (1994), Calazans (2004), McCloud (2005), Vergueiro e Ramos (2009) e Eisner (2010) são significativos para a discussão, visto que abordam sobre a História em Quadrinhos, seu uso no ensino e como recurso pedagógico, auxiliando na leitura e na produção textual. Além dos documentos e do referencial teórico se apresenta o projeto revista "Turma do Planeta Azul", que contribuiu na discussão e compreensão do uso dos quadrinhos em sala de aula. Dos contributos da História em Quadrinhos se destaca ainda o estímulo à imaginação, à criatividade e o desenvolvimento da criticidade.
\end{abstract}

Palavras-chave: Ensino. Leitura. Produção Textual. História em Quadrinhos.

\begin{abstract}
The use of comic books in the school context gains space due to its popularity as a means of mass communication, playfulness and visual appeal. Thus, it can represent the possibility of strengthening the teaching and reading practice, also contributing to the textual production, as well as to the understanding of different systematized contents. However, this was not always the case, there was a time when comic books were seen by parents, educators and other members of society as a means of alienating readers. In this context, the objective of this article is to present the path from comic books to their official entry into teaching, highlighting the trajectory, resistance and acceptability on the part of educators. For this, the article uses official documents such as the National Curriculum Parameters and the Common National Core Curriculum. Authors such as Iannone and Iannone (1994), Calazans (2004), McCloud (2005), Vergueiro and Ramos (2009) and Eisner (2010) are significant for the discussion, since they address comic books, their use in teaching and as a pedagogical resource, assisting in reading and textual production. In addition to the documents and the theoretical framework, it is presented herein the magazine project "Turma do Planeta Azul", which contributed to the discussion and understanding of the use of comics in the classroom. From the contributions of the comic book, the stimulation of imagination, creativity and the development of criticality are also highlighted.
\end{abstract}

Keywords: Teaching. Reading. Text Production. Comic Books.

\section{Introdução}

O processo de ensinar requer ações que contribuem para a formação dos educandos e para tanto exige do professor conhecimento e competências que possibilitam buscar, não só concepções teóricas, como práticas pedagógicas que permitem mediar a construção do conhecimento do aluno.

Nesse processo, o que compete a leitura, a formação do leitor é, de acordo com Larrosa (2005), multiplicar suas perspectivas, apurar seus sentidos e mostrar que a leitura é uma arte livre e infinita. Para Vilela (2009), não basta o professor apresentar os conteúdos na sala de aula, em forma de texto explicativos ou aulas expositivas, o maior desafio é fazer com que os assuntos desenvolvidos sejam significativos e propicie a interatividade entre texto e leitor.

Nesta busca por estratégias, no processo de ensino, destinadas à formação do leitor, o professor pode recorrer à História em Quadrinhos (HQ) como recurso pedagógico que, além de incentivar a leitura, auxilia no desenvolvimento dos alunos, seja pela facilidade de compreensão dos conteúdos sistematizados da disciplina ou pela relação que esta apresenta com os demais conceitos. Segundo Vilela, "A leitura compartilhada de quadrinhos na sala de aula pode ser uma forma de abrir 'uma janela para o mundo' despertar o interesse dos alunos por coisas novas" (2009, p. 79).

Nesse sentido, entende-se ser possível por meio da HQ, denominado por Eisner (2010) como arte sequencial, uma forma artística e literária que lida com a disposição 
de figuras ou imagens e palavras para narrar ou dramatizar, formar cidadãos leitores capazes de atuar no contexto social dialogando e produzindo novos textos. Trata-se de um gênero que se caracteriza pela sequência dos quadros combinando imagem e texto, personagens e balões para representação da fala e do pensamento.

Considerando os argumentos apresentados, este artigo aborda o percurso da HQ até sua inserção no processo de ensino, mediante pesquisa bibliográfica, consulta a documentos oficiais e norteadores como os Parâmetros Curriculares Nacionais (PCN) e a Base Nacional Comum Curricular (BNCC) e o exemplo das HQ "Turma do Planeta Azul". O material consultado permitiu discutir e refletir sobre a trajetória e o uso das HQ como recurso capaz de subsidiar o processo de aprendizagem, especialmente, a leitura e a escrita.

\section{Material e Métodos}

Trata-se de um artigo de caráter qualitativo e bibliográfico. Minayo (2003) enfatiza que a pesquisa qualitativa é o caminho percorrido pelo pensamento e ocupa um espaço "central na teoria" discutindo o "conjunto de técnicas".

A discussão apresentada é fruto de pesquisa bibliográfica, proveniente da etapa de levantamento e construção do referencial teórico para pesquisa sobre o uso de HQ no ensino para a formação do leitor e produção textual. Gil (2002, p. 44) define a pesquisa bibliográfica como aquela que é “desenvolvida com base em material já elaborado, constituído principalmente de livros e artigos científicos".

A escolha pela pesquisa bibliográfica não se caracteriza apenas como pré-requisito para a realização de uma abordagem. Nesse contexto, a pesquisa bibliográfica implica em conhecer, organizar e mencionar as informações do objeto de estudo, compreendendo que o conhecimento não deve ser aleatório, mas ordenado possibilitando a aproximação do leitor com o objeto a partir de fontes bibliográficas.

Para isso, recorre-se a autores como: Iannone e Iannone (1994), Calazans (2004), McCloud (2005), Larrosa (2005), Vergueiro e Ramos (2009), Vilela (2009) e Eisner (2010), além dos PCNs e a BNCC para realizar a discussão sobre a utilização das HQ como estratégia de ensino capaz de criar situações significativas para o processo de aprendizagem da leitura e escrita. Ainda, para evidenciar o uso em sala de aula e como recurso pedagógico se apresenta reflexões a partir da HQ "Turma do Planeta Azul”.

\section{Resultados e Discussão}

As Histórias em Quadrinhos (HQ) há séculos encantam gerações, sem dúvida, são vistas como um meio de comunicação que atinge um grande público. Desse modo, para tratar sobre as HQ, objeto desse artigo, opta-se por um formato linear e crescente da origem dos quadrinhos à inserção do gênero no ensino. A intenção foi delinear o percurso da História em Quadrinhos, a concepção do gênero e sua contribuição para produção de texto e a formação do leitor no contexto escolar. Além disso, apresenta-se o caso analisado por esta pesquisa, a história em quadrinhos "Turma do Planeta Azul" da Fundação Mokiti Okada.

Embora os primeiros registros da HQ, nos moldes que se conhece hoje, datam de meados dos séculos XIX, ao retroceder um pouco mais na história se observa que desde o início da humanidade, o ser humano utilizava de desenhos (imagem gráfica) na busca pela sobrevivência e apoiado na necessidade de comunicação. Esses desenhos, conhecidos como pinturas rupestres, registravam nas cavernas cenas que representavam situações do cotidiano e orientações para as gerações sucessoras. Essa afirmação corrobora com a colocação de Leila Iannone e Roberto Iannone publicada em seu livro $O$ mundo das histórias em quadrinhos "Estudiosos apontam as inscrições que nossos antepassados deixaram nas cavernas no período pré-histórico como a origem mais remota das histórias em quadrinhos" (1994, p. 10).

No olhar dos autores, considerando que a História em Quadrinhos é o registro de uma narrativa de um fato ou acontecimento através de desenhos e textos sequenciais, que apresentam linguagem verbal ou não verbal, os desenhos registrados nas cavernas são, sem dúvida, os primeiros rabiscos da arte sequenciada, denominação utilizada por Will Eisner (2010) para a História em Quadrinhos.

É nesta perspectiva que McCloud define HQ como “imagens pictóricas e outras justapostas em sequência deliberada destinadas a transmitir informações e/ou a produzir uma resposta no espectador" (2005, p. 20). Essa afirmação nos permite pensar que desde os desenhos registrados nas cavernas ou uma pintura, como parte de uma sequência e com a intencionalidade de narrar um acontecimento, são fortes indícios do princípio da origem dos quadrinhos.

No entanto, os registros oficiais das HQs com as características conhecidas, atualmente, começaram a surgir ao final do século XIX, na Europa e nos Estados Unidos, disseminada para outros países. Entre os precursores que se destacaram neste período se encontra o suíço Rodolphe Topffer com a criação do romance Monsieur Vieux-Bois (1827). Suas ilustrações eram permeadas pela originalidade e capacidade de registrar cenas riquíssimas de imaginação.

Mais tarde, outro grande precursor foi o alemão Wilhelm Busch com a obra Max e Moritz (1865), que registrava as peripécias de dois garotos que se apresentavam como figuras cômicas. Para Busch, a sociedade era fonte de inspiração para suas criações e o humor satírico um aliado na hostilização da burguesia. Na Inglaterra, a proeminência ficou a cargo de William F. Thomas e Tom Brown, com os personagens Ally Sloper, Willie e Tim, respectivamente. Segundo Iannone e Iannone (1994), o trabalho de ambos é considerado como a última versão moderna das HQ.

Nesse contexto, não se pode deixar de mencionar o francês Marie Louis Georges Colomb, conhecido pelo pseudônimo de 
Christophe, criador dos personagens da Família Fenouillard (1889), que é um inovador pelos movimentos e detalhes em suas ilustrações, além de um vocabulário de alto nível. Contudo, foram as obras do norte-americano Richard F. Outcault com o personagem "The Yellow Kid" (1895) e do alemão naturalizado norte-americano Rudolph Dicks, cujos personagens eram Hans e Fritz, que instigou uma disputa entre os maiores jornais de renome.

Assim, as publicações das revistas de HQ foram se corporificando, conquistando o mercado internacional e consagrando os chamados caricaturistas europeus, americanos e asiáticos. A princípio, de cunho político, os temas eram representados por desenhos simples, sem texto e de fácil compreensão. Com a expansão do mercado e a busca incessante por novas histórias surge um processo de rivalidade e de concorrência acirrada, levando os caricaturistas a redefinirem e reestruturarem as histórias que ganham características específicas da arte sequenciada.

No Brasil, os primeiros registros das HQ, considerado como precursor, é do italiano Ângelo Agostini, em 1864. Seu trabalho inovador ganhou repercussão nacional e os quadrinhos viraram um sucesso, a década de 1930 pode ser considerada um marco histórico. -

Nesse período Roberto Marinho, fundador do grupo Globo, envia Adolfo Aizen, um jovem jornalista considerado o maior incentivador dos quadrinhos, no Brasil, para os Estados Unidos em busca de novos laços empresariais. Ao retornar, encantado com o formato e com as histórias, Aizen expõe suas ideias a Marinho sem muito êxito. Este fato levou o jornalista a apresentar o projeto ao diretor do jornal "A Nação" que, prontamente, acolheu e lançou o Suplemento Infantil com edições diárias no modelo americano de $\mathrm{HQ}$, publicando os maiores sucessos dos Estados Unidos, tais como: Agente Secreto X-9, Flash Gordon, Mandrake, Tarzan e histórias inéditas de Walt Disney.

Para os autores Santos, Cruz e Vieira (2011), o sucesso extraordinário do Suplemento Infantil entre os jovens leitores e a ambição empresarial desperta em Marinho o desejo de lançar uma edição direcionada a esse público e, assim, nasce o Globo Juvenil e a revista Gibi. No Brasil, o termo gibi se torna sinônimo de "história em quadrinhos", com edições de personagens exclusivamente estrangeiros e com a participação de Nelson Rodrigues, ainda um roteirista desconhecido que fazia adaptações de clássicos da literatura para as revistinhas.

De acordo com Vergueiro (2018), o período de pósguerra (Guerra Fria) desencadeou um ambiente hostil para os quadrinhos, e abre espaço para as críticas desenfreadas do psiquiatra alemão Fredric Wertham. O autor atribuía a leitura das HQ como a principal causa das anomalias do comportamento delinquente das crianças e jovens da sociedade americana. Entre as diversas teses que defendia, o autor afirmava que a leitura de Batman e Robin incentivava a homossexualidade.

As críticas de Wertham causaram um impacto desastroso para o mercado dos quadrinhos, levando a Association of Comics Magazine, a implantar o Comics Code (Código de Ética das Histórias em Quadrinhos). Não demorou muito para que os demais países adotassem a medida e como afirma Vergueiro (2018, p. 13) "visava garantir a pais e educadores que o conteúdo das revistas não iria prejudicar o desenvolvimento moral e intelectual de seus filhos e alunos".

No Brasil, além do código intitulado "Código de Ética dos Quadrinhos" que orientava a edição das revistas, também foi criado um selo semelhante ao dos Estados Unidos que fixado na revista garantia a qualidade do conteúdo como leitura apropriada para crianças e jovens. No entanto, apesar da primeira determinação do código nacional mencionar que "as histórias em quadrinhos devem ser um instrumento de educação, formação moral, propaganda dos bons sentimentos e exaltação das virtudes sociais e individuais", sua leitura continuava a ser estigmatizada, de acordo com Vergueiro (2018, p. 16) pelas camadas ditas "pensantes" da sociedade.

No olhar desta sociedade, a HQ ocasionaria na criança atraso no desenvolvimento mental e a afastaria de conhecimentos considerados "eruditos", provocando danos no desempenho escolar. Vergueiro (2018, p.10) explica que essa sociedade considerava a leitura dos quadrinhos como prejuízo ao estudo e, assim sendo, o uso deste material no contexto educacional não era recomendado:

Consequências ainda mais aterradoras como o embotamento do raciocínio lógico, a dificuldade para apreensão de ideias abstratas e o mergulho em ambiente imaginativo, considerado prejudicial ao relacionamento social e afetivo de seus leitores.

Contudo, a partir da década de 1970, com o desenvolvimento tecnológico e a diversidade de abordagens dos Estudos Culturais, surgem novas compreensões sobre os meios de comunicação de massa como o cinema, o rádio, a televisão e a história em quadrinhos. Assim, em face aos novos desafios imposto pelo cenário contemporâneo, teóricos buscaram desenvolver um novo olhar sobre o impacto das HQ na Educação:

Por um lado, gradativamente elas passam a ser entendidas pela sociedade não mais como leitura exclusiva de criança, mas sim, como uma forma de entretenimento e transmissão de saber que podia atingir diversos públicos e faixas etárias. Por outro, paulatinamente deixavam de ser vistas de forma pejorativa ou preconceituosa, inclusive nas áreas pedagógicas e acadêmicas (VERGUEIRO; RAMOS, 2009, p. 9).

Dessa forma, ainda que timidamente, representou uma mudança significativa para o despertar do uso dos quadrinhos no contexto escolar. Embora, o início deste despertar tenha sido na Europa, sua propagação se estendeu em outras partes do Mundo. Vergueiro (2018, p.17) enfatiza que "aos poucos, o 'redescobrimento' das HQ fez com que muitas das barreiras ou acusações contra essas fossem derrubadas e anuladas", favorecendo a proximidade entre HQ e práticas pedagógicas.

A medida em que a sociedade compreendia que a leitura das HQ não era somente um instrumento de entretenimento, 
mas também uma fonte que possibilitava a comunicação de diferentes saberes, foram gradativamente sendo inseridas nos livros didáticos. Paulatinamente, estudos demonstravam que a leitura deste gênero favorecia não só a compreensão dos temas abordados, como despertava o senso crítico dos alunos, assim apresentavam resultados satisfatórios no processo de aprendizagem.

Para Calazans (2004), a HQ é uma forma universal de comunicação global por ser uma leitura espontânea e prazerosa, um recurso didático riquíssimo que auxilia os professores em todos os níveis de ensino, e assim o fortalecimento do uso deste gênero enquanto recurso didático ficou mais contundente com a promulgação da Lei de Diretrizes e Bases da Educação Nacional (LDB), em 20 de dezembro de 1996. A LDB enfatizava a necessidade do ensino de diferentes linguagens e manifestações culturais para a formação do aluno nos Ensinos Fundamental e Médio.

Na concepção de Vergueiro (2018), as HQ apresentam uma interação contínua entre as linguagens verbal e não verbal. Isso permite, em tempo real, a compreensão clara da mensagem em sua plenitude, permitindo uma comunicação rápida entre autor da $\mathrm{HQ}$ e leitor, consequentemente, uma aprendizagem significativa e enriquecedora. Corroborando com a ideia de Vergueiro, Ramos (2010) defende a premissa de que os quadrinhos possibilitam perceber a "linguagem" em uma nova perspectiva de olhar mais "crítico e fundamentado". Nesse sentido, ampliam os olhares e despertam um interesse e prazer maior dos alunos pela leitura por meio das relações cognitivas.

No entanto, foi a elaboração dos Parâmetros Curriculares Nacionais (PCNs) (BRASIL, 1997) que propiciou uma nova forma de conceber o uso das HQ, enquanto prática pedagógica, e reiterada na Base Nacional Comum Curricular (BNCC) (BRASIL, 2018). Esses documentos reforçam o objetivo de proporcionar aos alunos uma aprendizagem através de variadas práticas de linguagem "A BNCC procura contemplar a cultura digital, diferentes linguagens e diferentes letramentos, desde aqueles basicamente lineares com baixo nível de hipertextualidade até aqueles que envolvem a hipermídia" (BRASIL, 2018, p.70).

Nas palavras de Vergueiro e Ramos (2009), os parâmetros de Artes e Língua Portuguesa do Ensino Fundamental aludem a necessidade de desenvolver no aluno a capacidade de realizar uma leitura competente não só das $\mathrm{HQ}$, como de demais formas artísticas como desenhos animados, fotografias e vídeos, incluindo assim, uma prática pedagógica que fomenta a leitura dos elementos verbais e não verbais. O documento menciona, ainda, as referências específicas à charge e à leitura crítica que esse gênero demanda:

Os PCNs para o Ensino Médio destacam a importância dos diversos gêneros dos quadrinhos como fontes históricas e de pesquisas sociológica". No segundo caso, assinalam que charges, cartuns e tiras são "dispositivos visuais gráficos que veiculam e discutem aspectos da realidade social, apresentando-a de forma crítica e com muito humor

\section{(VERGUEIRO; RAMOS, 2009, p. 11).}

Nesse contexto, os parâmetros de linguagem do Ensino Médio ao fazer menção do uso das HQ como manifestação artística veiculada aos aspectos sociais proporcionam ao aluno uma reflexão sobre diferentes temáticas que permeiam no histórico-social.

Convém destacar, ainda, que o reconhecimento da importância da HQ, enquanto instrumento pedagógico, possibilitou outro destaque nos PCNs, agora nos parâmetros de Língua Estrangeira, no qual ressalta a necessidade de levar para sala de aula, textos com os quais os alunos têm uma maior proximidade e que favoreça o ensino da Língua Estrangeira. Tal colocação pode ser constata neste trecho "a determinação dos conteúdos referentes aos textos orais e escritos se pauta por tipos com os quais os alunos estão mais familiarizados como usuários de sua língua materna: pequenas histórias, quadrinhas, histórias em quadrinhos" (BRASIL, 1998, p.74).

Com relação a $\mathrm{BNCC}$, o documento recomenda a $\mathrm{HQ}$ em diferentes momentos e estabelece competências específicas de linguagens que precisam ser garantidas ao Ensino Fundamental, em que se compreende que os quadrinhos podem ser utilizados, entre essas:

1. Compreender as linguagens como construção humana, histórica, social e cultural, de natureza dinâmica, reconhecendo-as e valorizando-as como formas de significação da realidade e expressão de subjetividades e identidades sociais e culturais.

4. Utilizar diferentes linguagens - verbal (oral ou visualmotora, como Libras, e escrita), corporal, visual, sonora e digital -, para se expressar e partilhar informações, experiências, ideias e sentimentos em diferentes contextos e produzir sentidos que levem ao diálogo, à resolução de conflitos e à cooperação (BRASIL, 2018, p. 65).

Ainda com relação à área de linguagens, mais especificamente em competências de Língua Portuguesa para o Ensino Fundamental, em que se compreende o gênero quadrinho como recurso, a BNCC (BRASIL, 2018, p. 87) coloca que:

9. Envolver-se em práticas de leitura literária que possibilitem o desenvolvimento do senso estético para fruição, valorizando a literatura e outras manifestações artístico-culturais como formas de acesso às dimensões lúdicas, de imaginário e encantamento, reconhecendo o potencial transformador e humanizador da experiência com a literatura.

Os quadrinhos foram também sendo corporificado no Exame Nacional do Ensino Médio (ENEM), cujo objetivo é avaliar o nível de aprendizagem dos alunos. O exame considera que no percurso escolar, o aluno adquiriu certas competências necessárias para a compreensão de diversas linguagens. $\mathrm{O}$ exame propõe avaliar e analisar a leitura, seus modos e tipos que ultrapassam os limites da decifração linguística e adentram em uma visão de Mundo, que transcende a decodificação da escrita para uma compreensão holística.

Pautado no reconhecimento de que as HQ favorecem a compreensão dos temas abordados e facilitam o processo 
de ensino e aprendizagem, o Governo Brasileiro, em 2006, incluiu pela primeira vez o gênero no Programa Nacional Biblioteca na Escola (PNBE). Inicialmente, os livros eram adaptações de clássicos literários direcionados apenas para o Ensino Fundamental e foram, gradativamente, sendo ampliados e, em 2009, os quadrinhos voltados para o Ensino Médio chegam ao PNBE. Antes desqualificada no contexto escolar, a HQ se torna recurso para o incentivo à leitura. Para Ramos (2018, p.13):

Veem se uma outra relação entre quadrinhos e educação, bem mais harmoniosa. A presença deles nas provas de vestibular, a sua inclusão no PCN (Parâmetro Curricular Nacional) e a distribuição de obras ao ensino fundamental (por meio do Programa Nacional Biblioteca na Escola) levaram obrigatoriamente a linguagem dos quadrinhos para dentro da escola e para a realidade pedagógica do professor.

Considerando a evolução da HQ e as possibilidades que representam para trabalhar a leitura e também a escrita, e por acreditar que as $\mathrm{HQ}$, além de proporcionarem o prazer da leitura, surgem como uma forma divertida de inserir diversas temáticas e conhecimento, a Fundação Mokiti Okada elaborou, em 1989, o projeto-piloto "Planeta Azul: por um mundo melhor". Em 2001, foi publicada sua primeira revista, cujo objetivo, junto a escola, é formar sujeitos capazes de superar as dificuldades de leitura e enfrentar os desafios da vida em sociedade a partir dos quadrinhos.

Atualmente, a revista Turma do Planeta Azul publicada pela fundação em formato de história em quadrinhos circula, especialmente nas escolas. Cada edição é composta por argumentos de histórias vividas pelos alunos, em sala de aula, em suas famílias e/ou na sociedade e adaptadas aos personagens da HQ. As histórias abordam temas como: cidadania, preservação do meio ambiente, respeito, limpeza e organização, alimentação saudável, entre outros.

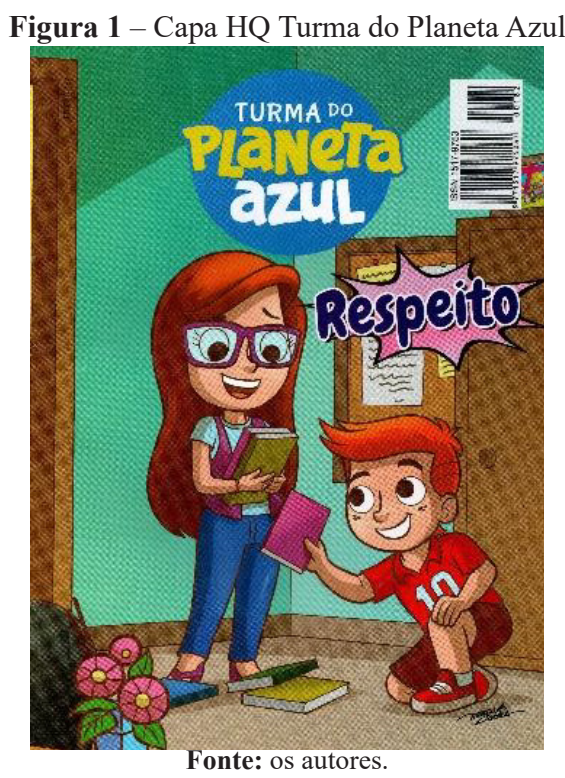

Os quadrinhos publicados na revista chamam a atenção dos alunos por serem lúdicos, de fácil entendimento, compreensão e uma diversidade de temas presentes no contexto social. Estes aspectos fortalecem o ensino e contribui para a produção textual e a formação do leitor, pois está associada com a forma de entendimento das crianças facilitando a compreensão, fatores que tornam a leitura atrativa e prazerosa, despertando o gosto pela prática e a internalização de novos conhecimentos. Para isso, a metodologia do Projeto Planeta Azul contempla, além da leitura, atividades como pensamento da semana, livro da aprendizagem, roda da leitura e elaboração e publicação dos roteiros para HQs.

Figura 2 - Fragmento de uma HQ Turma do Planeta Azul

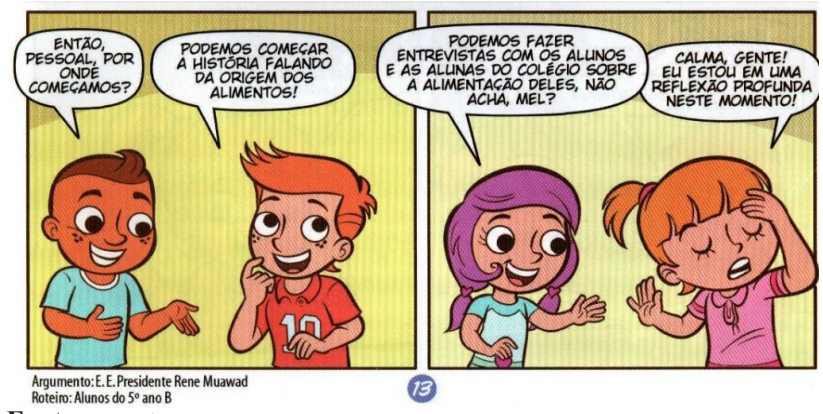

Fonte: os autores.

Os conteúdos abordados nas histórias das HQ Turma do Planeta Azul trazem situações reais como cooperação, cuidado com o meio ambiente, respeito com o outro, amizade, solidariedade, compromisso. Partindo das vivências, o conteúdo vai sendo sistematizado, favorecendo a pesquisa e o desenvolvimento da criticidade, que culminam na transformação de situações e questões cotidianas em HQ.

As HQ, além de proporcionar o prazer e entretenimento, constituem uma fascinante demonstração da criatividade humana. A forma e a estrutura desta arte narrativa mostram ao aluno a vivacidade do discurso direto presente nas histórias, esta vivacidade é provocada sobretudo pela variedade de expressões, de dicções e de termos que entram em sua composição.

Figura 3 - Fragmento de uma HQ Turma do Planeta Azul

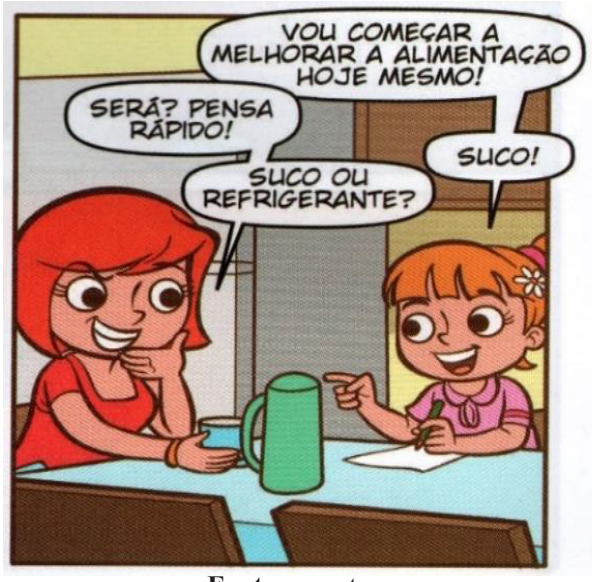

Fonte: os autores.

Segundo Alves (2001), a utilização da HQ na infância fortalece o ensino e o desenvolvimento da prática da leitura 
e contribui para a produção de texto e a formação do leitor. Para o autor, isto ocorre porque a leitura está desvinculada de determinado tempo histórico, além de ser mais conexa com a forma de entendimento das crianças, facilitando a compreensão do texto. Estes fatores tornam a leitura mais atrativa e prazerosa, porque as narrativas dos quadrinhos são compostas por elementos visuais e verbais.

Na metodologia Planeta Azul, a cada nova história lida, trabalha-se primeiro a oralidade com reflexão sobre os pontos abordados, a identificação dos personagens e suas atitudes. $\mathrm{Na}$ sequência é escolhida uma forma de registro, como a representação escrita da compreensão dos alunos sobre o tema. À medida que as histórias vão sendo trabalhadas, os alunos em um processo contínuo se apropriam da leitura e da escrita. A cada novo contato com a revista e com a leitura de suas histórias surgem perguntas e questões são levantadas (NAKAMURA; VOLTOLINI; BERTOLOTO, 2020). Considerando o que preconiza a BNCC, que prega o uso de diferentes linguagens para exercitar a curiosidade intelectual, a investigação e a criatividade, a HQ em questão se mostra oportuna para o desenvolvimento de competências e habilidades previstas no documento.

A Figura 4 mostra a publicação de uma história em formato HQ desenvolvida, em sala de aula, com uma turma do $4 .^{\circ}$ ano do Ensino Fundamental de uma escola pública, a partir do uso da metodologia e das HQ Turma do Planeta Azul.

Figura 4 - HQ Turma do Planeta Azul produzida durante atividade

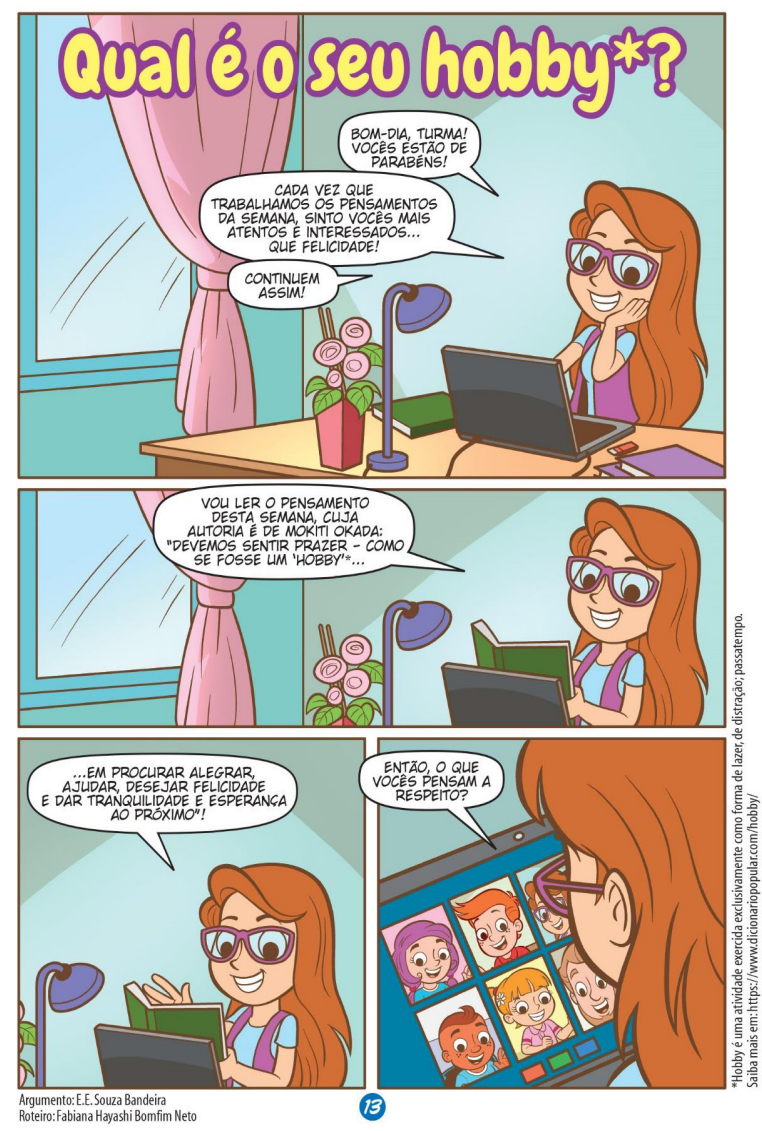

Fonte: os autores.
A utilização das HQ, no contexto escolar, a exemplo da "Turma do Planeta Azul", enquanto metodologia ludopedagógica se constata que não só potencializa a leitura e a escrita, como também permite ao aluno ser sujeito ativo na construção de seus conhecimentos. Analisando a partir do que a BNCC recomenda, as HQ são mencionadas no planejamento e produção da escrita como estratégia de leitura de diferentes gêneros, visando o desenvolvimento autônomo e a compreensão; produção de textos através de narrativas ficcionais e como forma de expressão, sendo essas algumas das menções ao gênero no referido documento e que corroboram com a prática apresentada.

Quanto ao uso dos quadrinhos, em sala de aula, Vergueiro (2018) afirma que não existem regras. Desse modo, cabe ao professor a escolha do conteúdo e da metodologia mais adequada às necessidades de ensino, seja para a introdução ou sensibilização de um tema, ou para aprofundamentos de conceitos, respeitando sempre o nível de conhecimento e compreensão dos alunos. Contudo, o autor alerta:

Os quadrinhos não podem ser vistos pela escola como espécie de panaceia que atende a todo e qualquer objetivo educacional, como se eles possuíssem alguma característica mágicas capaz de transformar pedra em outro. Pelo contrário, deve-se buscar a integração dos quadrinhos a outras produções industriais editorial, televisiva, radiofônica, cinematográfica etc., tratando todos como formas complementares não como inimigas ou adversárias na atenção dos estudantes (VERGUEIRO, 2018, p. 27).

O gênero história em quadrinhos pode ser um valioso recurso pedagógico, seja para o estímulo à leitura ou para a produção textual. No entanto, para que a prática pedagógica com os quadrinhos possibilite resultados eficientes é fundamental que os professores, além de incentivarem a leitura, em sala de aula, compreendam sobre elementos da linguagem presentes nas narrativas e desenvolvam atividades de leitura e de produção com esses objetivos.

\section{Conclusão}

É possível afirmar que as HQ surgem como uma fascinante arte de expressão e criatividade. Ao longo de sua trajetória, apesar dos desafios e obstáculos, foi amadurecendo e conquistou espaço no contexto educacional. Não somente como entretenimento, mas também instrumento de comunicação, que por meio das narrativas ilustradas por desenhos e textos inter-relacionados com informações, desempenha um papel importante na formação do leitor.

A partir da abordagem apresentada neste artigo, que teve como mote a trajetória da HQ até seu ingresso oficial no contexto escolar, além de mostrar alguns aspectos de uma experiência, em sala de aula, com o uso dos quadrinhos, tendo como base a metodologia da revista Turma do Planeta Azul e se espera instigar o desejo de buscar e ampliar a discussão sobre quadrinhos e sala de aula, especialmente, para o incentivo à leitura e produção textual. Além do recorte de pesquisa bibliográfica que fundamenta o artigo e a experiência 
mencionada, evidencia-se que a BNCC, documento norteador da Educação Básica no país corrobora com os apontamentos expostos sobre práticas de ensino e aprendizagem com o uso do gênero textual história em quadrinhos.

\section{Referências}

ALVES, J. M. Histórias em quadrinhos e Educação Infantil. Psicol. cienc. prof., Brasília, v. 21, n. 3, p. 2-9, 2001. doi: https://doi. org/10.1590/S1414-98932001000300002.

BRASIL. Base Nacional Comum Curricular. Brasília: MEC, 2018.

BRASIL. ENEM - Exame Nacional do Ensino Médio. Documento Básico. Instituto Nacional de Estudos e Pesquisas Educacionais. Brasília: 2002.

BRASIL. $L D B$ - Lei de diretrizes e bases. Lei $\mathrm{n}^{\circ} 9.394$, de 20 de dezembro de 1996. Brasília: MEC, 1996.

BRASIL. Parâmetros Curriculares Nacionais (PCNs). Introdução. Ensino Fundamental. Brasília: MEC/SEF, 1997.

BRASIL. Parâmetros Curriculares Nacionais (PCNs). Língua Estrangeira. Ensino Fundamental. Terceiro e quarto ciclos. Brasília: MEC/SEF, 1998.

CALAZANS, F. M. de A. História em quadrinhos na escola. São Paulo: Paulus, 2004.

GIL, A. C. Como elaborar projetos de pesquisa. São Paulo: Atlas, 2002

IANNONE, L.R.; IANNONE, R.A. O mundo das histórias em quadrinhos. São Paulo: Moderna, 1994.
LARROSA, J. Nietzsche \& a Educação. Belo Horizonte: Autêntica, 2005.

MCCLOUD, S. Desvendando os Quadrinhos. São Paulo: M. Books do Brasil, 2005.

MINAYO, M.C.S. Pesquisa social: teoria, método e criatividade. Rio de Janeiro: Vozes, 2003.

NAKAMURA, L.O.O.; VOLTOLINI, A G.M.F.F.; BERTOLOTO, J.S. O uso de histórias em quadrinhos no ensino: teoria, prática e BNCC. Rev. Educ. Pública, v.20, n.29, 2020.

RAMOS, P. A leitura dos quadrinhos. São Paulo: Contexto, 2010.

RAMOS. P. Os quadrinhos em aulas de Língua Portuguesa. In: VERGUEIRO, W. et al. Como usar as histórias em quadrinhos na sala de aula. São Paulo: Contexto, 2018. p.65-86.

SANTOS, I.G.R.B.A; CRUZ, T.A.; VIEIRA, M.L.H. O desenvolvimento das histórias em quadrinhos no Brasil. e-Rev. LOGO, v.2, 2011.

VERGUEIRO, W. A linguagem dos quadrinhos uma "alfabetização" necessária. In: VERGUEIRO, W. et al. Como usar as histórias em quadrinhos na sala de aula. São Paulo: Contexto, 2018.

VERGUEIRO, W; RAMOS, P. Quadrinhos na educação: da rejeição à prática. São Paulo: Contexto, 2009.

VILELA, T. Quadrinhos de aventura. In: VERGUEIRO, W.; RAMOS, P. Quadrinhos na Educação: da rejeição a prática. São Paulo: Contexto, 2009. p.73-102.

WILL, E. Quadrinhos e arte sequencial: princípios e práticas do lendário cartunista. São Paulo: Martin Fontes, 2010. 